\title{
Penerapan Model Pembelajaran Kooperatif Two Stay Two Stray (TSTS) Mata Kuliah Mikrobiologi untuk Meningkatkan Aktivitas Belajar Mahasiswa Melalui Kegiatan Lesson Study Di Jurusan Pendidikan Biologi FKIP UNIPA
}

\author{
I. $\operatorname{Iwan}^{1)}$ \\ ${ }^{1)}$ Jurusan Pendidikan Biologi, FKIP, Universitas Papua \\ b.iwan@unipa.ac.id
}

\begin{abstract}
Lesson study has been carried out on $V$ semester students in microbiology courses in the Biology Education and Teaching and Education Faculty Study Program, University of Papua, in the odd semester of the 2017/2018 academic year. The lesson activity of this study aims to improve the process and quality of biology learning. The activities carried out were the activities of the lesson team of biological studies consisting of model lecturers and observers. Lesson Study activities are carried out as many as four open classes, each open class consists of four stages of activity, namely: plan, implementation, observation and reflection or see. Each stage of producing planning (Chapter Design, Lesson Design, RPS and assessment instruments). The learning process is carried out through the application of the Two Stay Two Stray type (TSTS) cooperative learning model. Data obtained through observations by observers. The results obtained in the open class activities show that: (1) increasing student activity, creativity and independence, (2) students' understanding of concepts that are considered difficult to improve, and (3) the quality of microbiology learning increases (4) Learning cooperative type TSTS through lesson study activities $(L S)$ can enhance collaboration and discussion between members of the lesson study team in planning and implementing learning, as well as reflection on learning activities (5) Can improve lecturer professionalism because initially lecturercentered learning turns into learning centered on college student.
\end{abstract}

Keywords: Lesson study, Quality of learning, Open class, Microbiology.

This is an open access article distributed under the Creative Commons 4.0 Attribution License, which permits unrestricted use, distribution, and reproduction in any medium, provided the original work is properly cited. $\odot 2018$ by author and Universitas Negeri Padang.

\section{PENDAHULUAN}

Belajar merupakan suatu usaha yang dilakukan seseorang untuk memperoleh suatu perubahan tingkah laku secara keseluruhan, sebagai hasil pengalamannya sendiri dalam interaksi dengan lingkungannya (Slameto, 1995: 2). Perlu kita ketahui bahwa tidak ada proses pembelajaran yang sempurna, maka diperlukan upaya untuk meningkatkan kualitas pembe lajaran. Selanjutnya Dikti (2008) menekankan bahwa proses pembelajaran diperguruan tinggi harus mengutamakan pola pembelajaran ber pusat pada mahasiswa. Uraian tersebut meng gambarkan begitu pentingnya keterlibatan mahasiswa secara aktif dan interaksi diantara mahasiswa selama proses pembelajaran. Oleh karena itu, mahasiswa harus didorong untuk memiliki motivasi dalam diri mereka sendiri, kemudian berupaya mencapai kompetensi yang diharapkan.

Capaian Pembelajaran mata kuliah mikro biologi menekankan pada penguasaan konsep dan aplikasi mikrobiologi dalam kehidupan sehari-hari. Dalam upaya pencapaian kompe tensi tersebut, perlu dirancang suatu pembe lajaran yang berpusat pada mahasiswa melalui pembelajaran kooperatif tipe Two Stay Two Stray. Model pembelajaran kooperatif tipe two stay two stray merupakan model pembelajaran kelompok dengan tujuan agar mahasiswa dapat saling bekerjasama, bertanggung jawab, saling membantu memecahkan masalah dan saling mendorong untuk berprestasi (Yusiriza, 2010).

Menurut Suprijono (2009), pembelajaran dengan metode TSTS dimulai dengan pembagi an kelompok. Guru menyampaikan permasalah an lalu didiskusikan. Setelah diskusi didalam kelompok selesai, dua orang dari tiap kelompok meninggalkan kelompoknya untuk bertamu ke kelompok yang lainnya. Anggota kelompok yang tidak mendapat tugas sebagai tamu mempunyai kewajiban menerima tamu dari kelompok lainnya. Tugas mereka adalah menya jikan hasil kerja kelompoknya kepada tamu tersebut. Dua orang yang bertugas sebagai tamu diwajibkan bertamu kepada semua kelompok. 
Jika mereka telah selesai melaksanakan tugas nya, mereka kembali ke kelompoknya masingmasing. Setelah kembali ke kelompok asal, baik peserta didik yang bertugas bertamu maupun mereka yang bertugas menerima tamu menye suaikan dan membahas hasil kerja yang telah mereka laksanakan. Pembelajaran seharusnya lebih banyak terfokus pada siswa. Pendapat ini sesuai dengan Baransano, dkk (2017) yang menyatakan bahwa pembelajaran harus berfokus pada kegiatan siswa atau pembelajaran berpusat pada siswa.

Model pembelajaran kooperatif TSTS ini memiliki tujuan agar mahasiswa di ajak untuk bekerjasama dalam menemukan suatu konsep. Penerapan model pembelajaran kooperatif TSTS akan mengarahkan mahasiswa untuk aktif, baik dalam berdiskusi, tanya jawab, mencari jawaban, menjelaskan dan juga menyimak materi yang dijelaskan oleh temannya. Selain itu, alasan menggunakan model pembelajaran TSTS ini karena terdapat pembagian kerja kelompok yang jelas tiap anggota kelompok, mahasiswa dapat bekerjasama dengan temannya, dapat mengatasi kondisi mahasiswa yang ribut dan sulit diatur saat proses belajar mengajar berlangsung. Menurut Munir dan Damopolii (2018), Rumbekwan dkk (2018) bahwa pembe lajaran kooperatif membuat pencapaian hasil belajar menjadi lebih baik.

Menurut Lie dalam Yogaswara (2012: 2) mengemukakan kelebihan model TSTS yaitu dapat diterapkan pada semua kelas atau tingkat an, kecenderungan belajar mahasiswa menjadi lebih bermakna, lebih bertujuan pada keaktifan, mendorong meningkatkan minat dan prestasi belajar mahsiswa. Sedangkan faktor penghambat dari model TSTS yaitu: membutuhkan waktu yang agak lama, mahasiswa cenderung tidak ingin belajar dalam kelompok, guru atau dosen membutuhkan banyak persiapan, guru atau dosen cenderung kesulitan dalam pengelolaan kelasnya.

Dalam upaya penerapan model pembela jaran kooperatif tipe TSTS yang lebih efektif yang mengarah pada peningkatan aktivitas belajar mahasiswa, maka perlu dirangkaikan dengan kegiatan LSLC. Hal ini sangat beralasan dikarenakan rangkaian kegiatan LSLC sangat menekankan pada aktivitas belajar mahasiswa. Disamping itu, hal-hal yang dikemukakan pada tahap refleksi merupakan data otentik dari hasil observasi, yang dijadikan dasar bagi perbaikan kualitas pembelajaran berikutnya. Meskipun menurut Ueno (2013), bahwa LSLC tidak mengutamakan penuntasan masalah dan kesulit an melainkan membagi permasalahan, berinter aksi, serta berpikir untuk mengatasi masalah secara bersama-sama. Uraian tersebut, menun jukkan pentingnya pengembangan kualitas pembela jaran melalui kegiatan lesson study for learning community sebagai usaha meningkat kan aktivitas belajar mahasiswa dan diharapkan dapat meningkatkan pengetahuan dasar dalam pembelajaran, meningkatkan profesionalisme pendidik, dan membangun komunitas masya rakat belajar.

Hasil Observasi pada Mahasiswa Pendi dikan Biologi Universitas Papua ditemukan bahwa aktivitas mahasiswa dalam proses pembelajaran masih kurang aktif. Ketika dosen mengajar banyak diantara mahasiswa yang asyik bercerita, main HP atau mengerjakan hal-hal yang tidak ada hubungannya dengan perkuliahan apalagi jika mata kuliah yang diajarkan seperti mata kuliah mikrobiologi yang menuntut pemahaman konsep dengan melalui keterlibatan langsung dari mahaMahasiswa itu sendiri. Hal tersebut membuat dosen berinsiatif untuk mengimplentasikan model pembelajaran aktif yang dapat melibatkan mahasiswa secara langsung dalam proses perkuliahan. Pembe lajaran yang awalnya berpusat kepada dosen harus berubah ke pembelajaran yang berpusat kepada mahasiswa. salah satu model pembe lajaran yang di rekomendasikan atau diterapkan adalah model pembelajaran Two Stay Two Stray yang dirangkai dalam kegiatan Lesson Study for Learning community (LSLC).

\section{METODE PENELITIAN}

Kegiatan lesson study dilaksanakan bulan Agustus sampai dengan September 2017, pada semester ganjil tahun akademik 20172018. Open lesson dilaksanakan pada Program Studi Pendidikan Biologi, Fakultas FKIP, Universitas Papua Manokwari. Subjek penelitian yakni mahasiswa pendidikan biologi semester $\mathrm{V}$ yang memprogramkan mata kuliah Mikrobiologi yang berjumlah 29 orang terdiri dari 6 Laki-laki dan 23 orang Perempuan. Kelompok diskusi yang terbentuk sebanyak lima (5) kelompok dengan masing-masing kelompok berjumlah 4-5 orang mahasiswa. Dalam setiap open lesson terdiri dari tahap plan, tahap do dan tahap see.

Kegiatan pada tahapan plan dilakukan secara kolaboratif oleh tim lesson study. 
Kegiatan ini meliputi indentifikasi masalah pembelajaran mikrobiologi, review atas pengalaman pembelajaran yang biasa dilakukan, persiapan silabus, merancang rencana pembe lajaran berbasis lesson study yang meliputi pembuatan lesson design dan chapter design, merumuskan metode, model atau teknik pembelajaran yang akan digunakan, membuat bahan ajar, membuat media pembelajaran, membuat lembar diskusi mahasiswa, membuat lembar observasi, dan persiapan alat yang dibutuhkan dalam proses pembelajaran serta peralatan dokumentasi. Tahapan do meliputi 2 kegiatan utama, yaitu pelaksanaan dan observasi proses pembelajaran. Pelaksanaan pembelajaran dilakukan sesuai dengan yang telah dirumuskan dalam tahapan plan. Observasi terhadap proses pembelajaran dilakukan untuk mencari fakta fakta yang muncul selama proses pembelajaran. Selama kegiatan observasi, para observer tidak diperkenankan saling berbicara. Tahapan see berupa kegiatan review, evaluasi atau refleksi terhadap proses pembelajaran yang telah berlangsung. See dalam penelitian ini dilaksana kan secara kolaboratif dengan melibatkan seluruh mahasiswa kelas sampel, bukan hanya antara observer dan dosen model saja. Pelaksanaan (see) berupa refleksi yang dilaku kan selama proses belajar mengajar berlang sung. Kegiatan refleksi dipimpin moderator merangkap pengamat atau observer. Observer lainnya adalah 3 orang dosen. Diskusi diarahkan pada: (1) berbagi dan menganalisis data, (2) upaya pencapaian tujuan pembelajaran dan perkembangan mahasiswa, dan (3) perbaikan yang perlu dilakukan terhadap rancangan proses pembelajaran. Segala masukkan dari kegiatan see dijadikan sebagai bahan untuk melakukan revisi dan perbaikkan tahapan plan ataupun do pada siklus ke dua. Teknik pengumpulan data dilakukan melalui teknik observasi terhadap aktivitas mahasiswa dan dosen model, angket, wawancara, dan teknik audio video. Data yang diperoleh dianalisis secara deskriptif kualitatif.

\section{HASIL DAN PEMBAHASAN}

Kegiatan Open Class pada siklus I dilakukan dengan tema pengenalan dan Sejarah Mikrobiologi. Perangkat pembelajaran yang meliputi bahan Bacaan, RPS, Lembar Kerja kerja mahasiswa (LKM), tes kognitif dan lembar kegiatan plan telah disusun sebelum kegiatan plan. Plan diikuti oleh 4 Dosen pendidikan
Biologi FKIP UNIPA antara lain; Jan H.Nunaki, Iwan, Aksamina M. Yohanita, dan Silvia H.Kusuma Sirait. Kegiatan Plan dilakukan di ruang dosen program studi Pendidikan Biologi FKIP UNIPA.

Do (Pelaksanaan) siklus I dilaksanakan pada hari kamis tanggal 31 Agustus 2017 jam 08.00 - 10.20 WIT di Ruangan 6 Lt 2 Pascasarjana Universitas Papua Pada Materi Pengenalan dan sejarah Mikrobiologi. Dosen model adalah Iwan, Observer antara lain; Benidictus Tanujaya, Jein Mumu, Apriani Sulu Parubak, Achmad Rante Suparman, Fredi,Silvia Hanna K.Sirait. Observer yang hadir terdiri dari 7 orang. Secara umum kegiatan perkuliahan berlangsung dengan baik. Mahasiswa tertarik dengan yang dijelaskan oleh dosen model dan mengikuti apa yang disampaikan oleh dosen. Pada saat proses pembelajaran berlangsung beberapa mahasiswa diminta oleh dosen model untuk membacakan tujuan pembelajaran sehingga mahasiswa terlihat antusias didalam mengikuti pembelajaran karena dilibatkan didalam penyampaian tujuan pembelajaran. Namun ketika memasuki awal materi terdapat beberapa mahasiswa yang terlihat sibuk dengan aktivitasnya sendiri, hal ini dikarenakan di awal dosen menyampaikan materi dengan metode ceramah, Mahasiswa terlihat menatap kedepan namun tatapannya terlihat hampa, hanya beberap orang yang terlihat aktif, setelah beberapa menit kemudian ketika dosen model memancing mahasiswa untuk bertanya maka mahasiswa sudah mulai terlihat antusias selanjutnya dosen model membagi mahasiswa menjadi 5 kelompok dan setiap kelompok terdiri dari 45 orang. Dosen model kemudian membagikan LKM untuk di diskusikan oleh seiap kelompok. Setiap kelompok mendapatkan materi yang berbeda untuk dikonstruksi. Diskusi kelompok berlangsung secara biasa, selanjutnya 2 orang dari kelompok tuan rumah akan bertamu ke kelompok lain sebagai tamu untuk mendapatkan penjelasan dari kelompok tuan rumah, selanjutnya tamu mohon diri dan seterusnya sampai kembali kekelompok asalnya masingmasing dan mencocokkan hasil informasi yang diperoleh dengan kelompoknya. Selanjut nya setiap kelompok mempresentasikan hasil diskusi kelompoknya dan kelompok lain dapat menanggapinya. Di kegiatan penutup dosen model mengarahkan mahasiswa untuk menyim pulkan pembelajaran 
Kegiatan Refleksi dilakukan setelah kegiatan pelaksanaan selesai dilaksanakan oleh dosen. Beberapa saran dan masukan selama refleksi diantaranya terdapat beberapa maha siswa yang terlihat kurang aktif seperti mahasiswa no.9 atas nama Damianus Wonmut dan Paulina yang merupakan mahasiswa asli papua yang perlu terapi khusus agar mahasiswa tersebut dapat aktif. Beberapa pembagian kelompok juga tidak heterogen sehingga terdapat satu kelompok yang hampir semuanya kurang aktif seperti mahasiswa No 3,No.6 No.8 dan No.11 Perlu disebar. Waktu diskusi kelompok masih kurang sehingga belum selesai di diskusikan oleh mahasiswa sudah berpindah ke kelompok lain. Namu secara umum observer menyatakan model pembelajaran yang diterap kan oleh dosen model sangat baik sekali karena dapat memberikan kesempatan kepada Maha siswa untuk mandiri bertanggung jawab dan menemukan konsep pembelajaran melalui informasi yang diperoleh setelah bertamu ke kelompok yang lain. Kelebihan pada open class I, antara lain: (1) Lembar Kerja mahasiswa menarik dan memudahkan mahasiswa untuk belajar,(2) waktu pembelajaran lebih efektif dan telah dimanfaatkan oleh mahasiswa, (3) mahasiswa terlibat aktif dalam pembelajaran, dan (4) kegiatan apersepsi sangat menarik dan mampu membangkitkan minat dan motivasi mahasiswa (5) pengunaan model pembelajaran TSTS dapat mengaktifkan mahasiswa. Beberapa ide atau gagasan observer setelah mengobservasi pembelajaran yaitu: (1) membimbing jalannya diskusi kelas oleh dosen model agar tidak dominasi oleh kelompok-kelompok tertentu dari mahasiswa, (2) pengaturan tempat duduk yang baik agar observer dapat mengamati aktivitas mahasiswa, (3) penggunaan media belajaran agar lebih dioptimalkan (4) Melakukan pembag ian kelompok mahasiswa yang heterogen agar merata sehingga dapat membantu temannya yang kurang mampu.

Plan (Perencanaan) pada siklus kedua dilakukan di ruang Dosen Prodi Pendidikan Biologi Universitas Papua yang diikuti oleh Iwan selaku dosen model, Jan H. Nunaki, Aksamina M.Yohanita, dan Silvia Hanna Kusuma Sirat. Pada tahap ini perangkat pembelajaran, Lembar Kerja mahasiswa, alat evaluasi dan lembar observasi lesson study sudah dipersiapkan, mencoba melakukan pendekatan kepada mahasiswa atas nama Damianus dan Paulina mahasiswa asli papua agar dapat mengikuti teman-temannya untuk aktif berdiskusi. Salah satu cara dengan memintanya untuk menyebutkan tujuan pembe lajaran/perkuliahan. Selanjutnya waktu untuk diskusi mahasiswa diatur sedemikian rupa sehingga dapat berjalan dengan baik dan efektif. Pembagian kelompok telah diupayakan secara heterogen dengan memperhatikan latar belakang kemampuan dari mahasiswa sehingga semua mahasiswa diupayakan agar aktif dalam kegiat an pembelajaran.

Do Siklus II dilaksanakan pada hari selasa tanggal 05 September 2017 Pukul 10.20 12.50 WIT di ruang 6 Lt.2 Gedung Pascasarjana Universitas Papua Pada Materi Bakteri. Dosen model adalah Iwan, Observer antara lain; Achmad Rante Suparman, Fredi, Silvia Hanna K.Sirait,Purwati dan Sri Wahyu Widyningsih. Observer yang hadir terdiri dari 6 orang. Mahasiswa tertarik dan menyimak apersepsi yang disampaikan oleh Dosen model karena dikaitkan dengan kehidupan nyata yang dialami seharihari oleh mahasiswa. Pada saat penyampai an tujuan pembelajaran mahasiswa dilibatkan untuk membaca tujuan sehingga materi terarah. Dosen model menyampaikan materi secara singkat sehingga mahasiswa terlihat antusias dan memperhatikan. Selanjutnya Dosen membagi mahasiswa menjadi 5 kelompok dan setiap kelompok terdiri dari 45 orang. Dosen model kemudian membagikan LKM untuk didiskusi kan oleh seiap kelompok. Setiap kelompok mendapatkan materi yang berbeda untuk dikonstruksi. Diskusi kelompok berlangsung secara biasa, selanjutnya 2 orang dari kelompok tuan rumah akan bertamu ke kelompok lain sebagai tamu untuk mendapatkan penjelasan dari kelompok tuan rumah, selanjutnya tamu mohon diri dan seterusnya sampai kembali kekelompok asalnya masing-masing dan menco cokkan hasil informasi yang diperoleh dengan kelompoknya. selanjutnya setiap kelompok mempresentasikan hasil diskusi kelompoknya dan kelompok lain dapat menanggapinya. Di kegiatan penutup dosen model mengarahkan mahasiswa untuk menyimpulkan pembelajaran sesuai dengan tujuan yang telah ditentukan.

Kegiatan See (Refleksi) pada siklus 2 dilakukan setelah kegiatan Do selesai dilaksana kan oleh dosen model. Beberapa saran dan masukan selama refleksi diantaranya terdapat mahasiswa yang di siklus I terlihat kurang aktif seperti mahasiswa no.9 atas nama Damianus Wonmut dan Paulina yang merupakan maha 
siswa asli papua setelah terapi dengan mendorong untuk terlibat dalam kegiatan diskusi maka akhirnya mahasiswa tersebut menjadi aktif dan sudah berani untuk bertanya dan mengemu kakan pendapat. Pembagian kelompok telah dibuat secara heterogen sehingga terlihat akivitas merata pada setiap kelompok, seperti mahasiswa No 3, No.6 No.8 dan No.11 telah disebar merata, namun tentunya beberapa orang masih kurang aktif. Waktu diskusi kelompok masih telah ditambahkan sehingga kerja kelompok menjadi efektif. Secara umum observer menyatakan model pembelajaran yang direrapkan oleh dosen model sangat baik sekali karena dapat memberikan kesempatan kepada mahasiswa untuk mandiri bertanggung jawab dan menemukan konsep pembelajaran melalui informasi yang diperoleh setelah bertamu ke kelompok yang lain sehingga aktivitas maha siswa cukup meningkat.

Kelebihan pada open class siklus 2, antara lain: (1) Mahasiswa sudah memahami materi yang diajarkan, (2) Mahasiswa dapat mengerjakan LKM dan mempresentasikannya dengan baik, (3) dosen model berhasil menjalan kan peran sebagai fasilitator diskusi dengan baik. Beberapa ide/gagasan observer setelah mengobservasi pembelajaran: (1) pengaturan tempat duduk lebih rapi, (2) perhatian dosen lebih menyeluruh terutama pada mahasiswa yang pada asal papua yang kurang mampu (3) diskusi kelas lebih dimaksimalkan. Pelaksanaan refleksi dicatat beberapa lesson learned yang berharga, antara lain sebagai berikut. (l) setiap kelompok akan ada mahasiswa yang pasif dan aktif. Hal ini normal terjadi. bukan berarti mahasiswa yang pasif tidak belajar, mahasiswa yang pasif tetap fokus pada kegiatan pembelajaran namun hanya membaca materi. Jika mahasiswa yang tidak aktif itu selalu demikian dalam berbagai kegiatan pembelajaran harus sering selalu diberi motivasi. (2). Hampir semua mahasiswa senang dengan proses pembelajaran melalui penerapan model pembe lajaran tipe Two Stay Two Stray.

Usaha perbaikan yang dilakukan dosen model dari siklus I ke siklus II dalam kegiatan lesson study merupakan cara yang sangat efektif. Model pembelajaran kooperatif tipe Two Stay Two Stray diharapkan menjadi solusi yang sangat tepat untuk diterapkan dalam proses pembelajaran demi peningkatan kualitas pembe lajaran. Pada siklus I terlihat pembagian kelom pok tidak heterogen sehingga beberapa maha siswa tidak mampu berdiskusi dengan teman kelompoknya. Posisi duduk dalam kelompok juga masih kurang tepat. Model pembelajaran yang diterapkan dirasa baru oleh mahasiswa sehingga mahasiswa masih kurang terbiasa dengan model tersebut. Dalam pembelajaran, beberapa mahasiswa terlihat kurang aktif dalam kegiatan pembelajaran.

Beberapa kelemahan yang ditemukan oleh dosen dan observer tersebut dapat menambah motivasi bagi dosen model untuk memperbaikinya. Perbaikan yang dilakukan oleh dosen pada siklus II adalah dengan membagi kelompok secara heterogen sehingga memudah kan dosen dalam membimbingnya yang terdiri dari 4-5 orang dalam satu kelompok. Setting posisi duduk yang awalnya terlihat masih tersebar dirubah menjadi tempat duduk melingkar yang di tengah - tengah sehingga memungkinkan observer dapat mengamati aktivitas dari mahasiswa tersebut. Dosen meminta kepada 2 orang setiap kelompok untuk bertamu ke kelompok lain dan 2 orang tinggal sebagai tamu dan bertugas untuk menjelaskan kepada setiap tamu yang datang. Setiap ada mahasiswa yang kurang aktif, maka dosen model mendatanginya untuk memberikan bimbingan agar mereka kembali aktif dalam kegiatan pembelajaran. Dengan adanya perbaik an tersebut akan mengurangi kebingungan dan kesulitan mahasiswa dalam melaksanakan kegiatan pembelajaran secara utuh. Dengan cara ini mahasiswa lebih mudah dalam menyelesai kan LKM yang ditugaskan kepada mahasiswa tersebut.

Tindakan positif dari dosen model dapat mengatasi kesulitan mahasiswa dalam pembe lajaran. Hal ini sesuai dengan pernyataan Susilo (2011) yaitu lesson study merupakan salah satu kegiatan untuk meningkatkan kualitas pembe lajaran. Hal ini senada dengan yang dikemuka kan oleh Syamsuri dan Ibrohim (2008) mengata kan bahwa dalam penerapan lesson study guru/dosen berusaha untuk mengubah proses pembelajarannya menjadi menjadi proses pembelajaran yang berkualiatas dan lebih efektif, dengan jalan mengamati, pengumpulan data, menganalisis data dan mengevaluasinya. untuk melihat bagaimana dampaknya maka dibantu oleh observer, dan selanjutnya merevisi rencana pembelajaran untuk kegiatan pembe lajaran berikutnya. Hasil pengamatan yang dilakukan oleh para pengamat menunjukkan bahwa dengan menggunakan model pembe 
lajaran TSTS pada mata kuliah mikrobiologi semakin meningkat dikarenakan mahasiswa terlibat secara langsung dan dosen model hanya bertugas sebagai fasilitator. Aktivitas mahasiswa terlihat sangat baik, hal itu ditunjukkan oleh mahasiswa yang sangat antusias berdiskusi dalam kelompoknya. Pernyataan tersebut sesuai dengan pendapat Santyasa (2009) yakni adanya suatu peningkatan perbaikan dalam praktik melaksanakan pembelajaran tentunya akan mengarah pada peningkatan hasil belajar dan proses belajar mahasiswa.

Aktivitas mahasiswa cukup meningkat tentu tidak terlepas dari usaha dosen bersama dengan pengamat dalam memperbaiki proses pembelajarannya. Langkah demi langkah dosen model selalu berusaha untuk memperbaiki rencana pembelajaran, memperbaiki cara mengajar, dan memperbaiki cara mengamati aktivitas mahasiswa. Keseluruhan perbaikan tersebut dilakukan oleh dosen model demi meningkatkan kualitas pembelajaran yang dilakukannya. Pernyataan tersebut didukung oleh Ibrohim (2009) bahwa kegiatan lesson study sesungguhnya akan memberikan pengaruh terhadap hasil belajar mahasiswa dikarenakan dalam kegiatan ini sering dilakukan perbaikan perbaikan dalam proses pembelajaran/ perkuliah an sehingga kesulitan-kesulitan yang dialami mahasiswa akan dapat teratasi dengan berjalan nya kegiatan lesson study oleh guru maupun dosen. Garfield dalam Ibrohim dan Syamsuri (2008) telah menambahkan juga bahwa lesson study itu sebagai suatu proses yang sistematis yang digunakan oleh guru /dosen untuk menguji keefektifan pembelajarannya demi meningkat kan hasil pembelajarannya yang secara tidak langsung juga membantu dalam meningkatnya hasil belajar para mahasiswanya.

Dengan keberhasilan penerapan lesson study dalam penelitian ini tidak terlepas dari dukungan dari pengamat saat berlangsungnya kegaitan pembelajaran di dalam kelas. Para pengamat melakukan pengamatan secara detail pada aktivitas mahasiswa dan tidak hanya kegiatan yang dilakukan oleh dosen model. Sekecil apapun aktivitas mahasiswa dapat dicatat oleh pengamat, sehingga hasil dari pengamatan oleh observer dapat digunakan sebagai bahan perbaikan kualitas pembelajaran mahasiswa di jurusan pendidikan biologi FKIP UNIPA Manokwari.

\section{KESIMPULAN}

Kesimpulan yang dapat diperoleh dari pelaksanaan lesson study (LS) adalah :

1. Pelaksanaan pembelajaran kooperatif tipe TSTS melalui kegiatan lesson study (LS) dapat meningkatkan kerjasama dan diskusi antara anggota tim lesson study dalam perencanaan dan pelaksanaan pembelajaran, maupun refleksi yang dilakukan terhadap kegiatan pembelajaran.

2. Pelaksanaan pembelajaran model kooperatif TSTS melalui kegiatan lesson study (LS) dapat meningkatkan aktivitas belajar Maha siswa selama proses pembelajaran hal tersebut tentunya dapat meningkatkan kuali tas pembelajaran.

3. Pembelajaran selama ini yang berpusat kepada dosen beralih ke pembalajaran yang berpusat kepada Mahasiswa

\section{DAFTAR PUSTAKA}

Azis, A. A. , Adnan, Muis, A. , Taiyeb, A. M., \& Faisal. (2013.) Penerapan Pembelajaran Kolaboratif Untuk Meningkatkan Aktivi tas Belajar Mahasiswa Kelas XI IPA 3 Melalui Lesson Study Berbasis Sekolah di SMA Negeri. Jurnal Bionature. Volume 14 (1), ( Hal. 3843.)

Baransano, A. Y., Yohanita, A. M., \& Damopolii, I. (2017). Penerapan Model Pembelajaran Picture and Picture untuk Meningkatkan Hasil Belajar Biologi Siswa Kelas XI IPA SMA YABT Manokwari. In Prosiding Seminar Nasional MIPA II Universitas Papua Tahun 2017 (pp. 273-280).

Dikti. (2008). Buku Panduan Pengembangan Kurikulum Berbasis Kompetensi Pendidik an Tinggi (Sebuah alternatif penyusunan kurikulum). Dikti. Jakarta.

Ibrohim. (2009). Pengaruh Model Implementasi Lesson Study dalam Kegiatan MGMP terhadap Peningkatan Kompetensi Guru dan Hasil Belajar Biologi Mahasiswa. Disertasi tidak diterbitkan. Malang: PPs UM.

Munir, M. K., \& Damopolii, I. (2018). Pengaruh Model Pembelajaran Make a Match terhadap Hasil Belajar Siswa Di Kelas VII SMP Yapis Manokwari. KEGURU" Jurnal Ilmu Pendidikan Dasar", 2(1), 120-129. 
Santyasa, I. W. (2009). Implementasi Lesson Study dalam Pembelajaran. Disajikan dalam "Seminar Implementasi Lesson Study dalam Pembelajaran bagi GuruGuru TK, Sekolah Dasar, dan Sekolah Menengah Pertama di Kecamatan Nusa Penida, Tanggal 24 Januari 2009. Universitas Pendidikan Ganesha.

Slameto. (1995). Belajar dan Faktorfaktor yang Mempengaruhinya, Jakarta: Rineka Cipta

Suprijono, A. (2009). Cooperatif Learning Teori dan Aplikasi PAIKEM,Yogyakarta: PT. Pustaka Pelajar

Susilo, H. (2011). Pengembangan Potensi Mahasiswa melalui Pembelajaran Sains yang Inovatif: Apa, Mengapa, dan Bagaimana?. Makalah disajikan dalam Seminar Nasional bertema Inovasi Pembelajaran Sains dalam Pengembangan Sumber Daya Manusia, Universitas Ronggolawe. Tuban, 22 Mei.

Prayitno, T. A \& Hidayati, N. (2015). Penerapan lesson study pada kegiatan praktikum mikrobiologi program studi pendidikan biologi IKIP budi utomo malang. Jurnal BIOEDUKASI Volume 9, Nomor 1. ISSN: 1693265X.

Rumbekwan, Y. O., Yohanita, A. M., \& Damopolii, I. (2018). Pengaruh Model Pembelajaran Cooperative Script terhadap Hasil Belajar Biologi di Kelas VIII SMP 11 Manokwari. JIPVA, 25-35.

Ueno, M. (2013)). Pembelajaran Kolaboratif dan Pendidikan Demokrasi. Makalah Disajikan pada ShortTerm Training on Lesson Study (STOLS) for Institute of Teacher Training and Education Personnel (ITTEP), Tokyo, 14 Oktober8 November.

Yogaswara, B. (2012). Penerapan Model embelajaran Two Stay Two Stray (Tsts) Untuk Meningkatkan Hasil Belajar Geografi Mahasiswa Kelas X-1 Sma Negeri 1 Purwosari Kompetensi Dasar Menganalisis Hidrosfer Semester Genap 2011/2012. Skripsi Universitas Negeri Malang.[Online] Tersedia di: http://jurnal online.um.ac.id/data/artikel/artikel9DB8A 2AD8497F61E2C5AC110 690968AB.pdf tanggal September 2017 